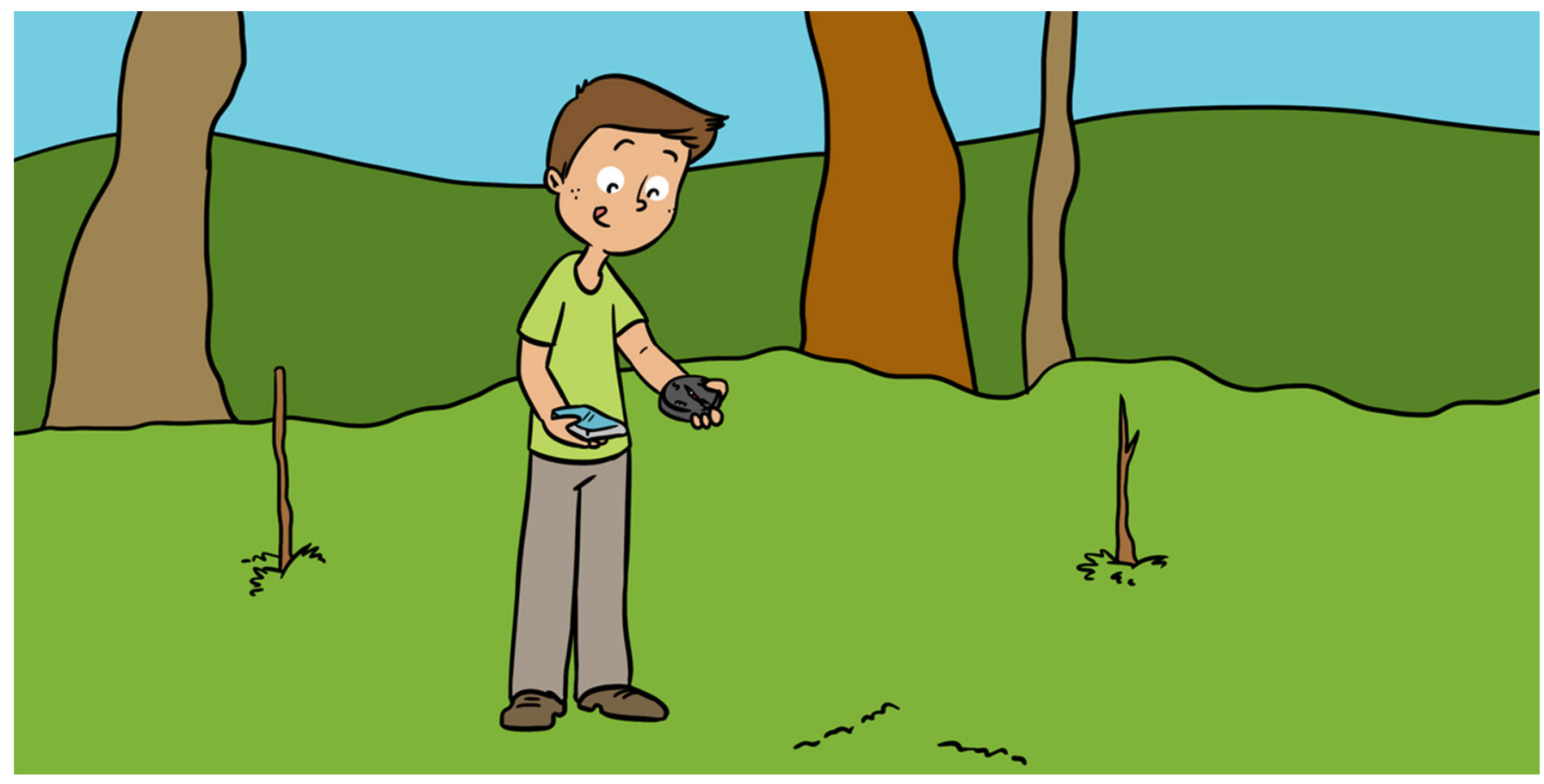

\title{
MAKING A MAP OF THE EARTH'S MAGNETIC FIELD
}

\section{Ciarán D. Beggan*}

British Geological Survey, Edinburgh, United Kingdom

YOUNG REVIEWER:

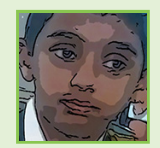

SASYAK

AGE: 10

\section{OUTER CORE}

The liquid metal layer within the Earth, starting about halfway to the center.
The Earth has a solid inner core and a liquid outer core, both made of iron and nickel. The metal carries an electrical current that is powered by the movement of the liquid. The electrical current creates a magnetic field that reaches out from the core to the surface of the Earth and beyond. The magnetic field formed by the Earth's core is expected to align with the axis of rotation, but it deviates a bit for reasons that are not well-understood. A compass needle generally does not point to true North (the axis of rotation of the Earth), but to the magnetic North pole. The angle between true North and magnetic North at any particular position on the Earth is called the declination angle. Maps of the declination angle are very complicated and because of the flow of the outer core, the position of magnetic North moves over time.

\section{INTRODUCTION}

\section{The Earth's Outer Core}

Planet Earth can be divided into four layers: the solid inner core at the center, the liquid outer core, the rocky mantle and the crust at the 
surface, which we live on. The core of the Earth is around 6,800 km wide and starts about halfway to the center of the planet (Figure 1b). It is made up of around nine-tenths iron and nickel [1]. The inner core is about the size of the moon. It is very hot $\left(>5,000^{\circ} \mathrm{C}\right)$ and is solid due to the extremely high pressure from the weight of the material above it.

Further away from the very center of the Earth is the liquid outer core, which is about the size of Mars. The metal is still extremely hot $\left(>3,000^{\circ} \mathrm{C}\right)$ but despite the high pressure, the outer core is actually very runny, as the heat overcomes the effects of the pressure. The outer core flows as easily as water on the surface of the Earth does. This means the metal is constantly moving and flowing, like the oceans. Similar to what happens when you quickly stir a cup of tea, the rapid rotation of the Earth once per day makes the fluid in the outer core spin too.

The core is trying to cool itself down. However, the rocky mantle between the core and the surface acts as a blanket, stopping the core from cooling too quickly. The core tries to find other ways to get rid of its excess heat and energy. One way to do this is by generating a magnetic field. The magnetic field can pass all the way to the Earth's surface, allowing a small amount of energy to be released by the core.

ELECTRICALLY CONDUCTIVE MATERIAL

A material that allows electricity to pass easily through it.

\section{ELECTRICITY CREATES A MAGNETIC FIELD}

Magnetism and electricity are physically linked-you usually get one when the other is created, and that also happens within the core. The liquid metal of the core is too hot to be a permanent magnet, like a fridge magnet, but it is an electrically conductive material, like a copper wire. Similar to the wires in your house, the liquid core carries a very large electrical current, which in turn creates a large magnetic field.

The electricity is created from the movement of the liquid metal, in a similar way to a wind turbine, which creates electricity from the motion of the blades. The electricity flows around the planet's equator in a very large loop and creates a strong magnetic field, which escapes the outer core. The magnetic field passes all the way to the Earth's surface and out into space.

It creates a bar magnet-shaped magnetic field (Figure 1a). The magnetic field extends out into space forming a "bubble" in which the Earth sits. This magnetic bubble shields the planet's atmosphere from the Sun's magnetic field, which otherwise would strip away Earth's atmosphere over billions of years. 
Figure 1

(a) An illustration of the magnetic field lines from a simple bar magnet, similar to the Earth's magnetic field. Like the Earth, the southern pole (labeled "S") is actually in the northern hemisphere. (b) The Earth's core is visible at the center of the planet. The rocky mantle and crust are transparent in this picture. The outer core is shown in orange, with the inner core shown by the darker sphere at the center. The magnetic field (blue lines) is created in the outer core. On the right is an artist's view of the Swarm magnetic satellite, which senses the compass direction changing as it flies through the Earth's magnetic field in its orbit (gray line). ${ }^{\circ} \mathrm{ESA} /$ ATG Medialab. Figure 1a, https://commons. wikimedia.org/wiki/ File:Earth's_magnetic_ field_pole.svg

\section{DECLINATION}

The angle between magnetic North and true North.

\section{MAGNETIC NORTH}

The point on the surface of the Earth where the magnetic field points directly toward the Earth's center. (a)

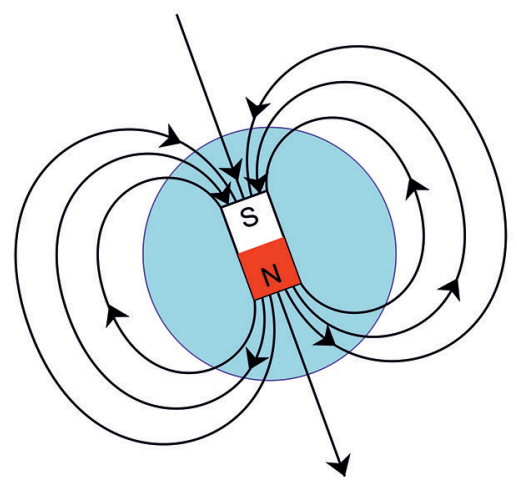

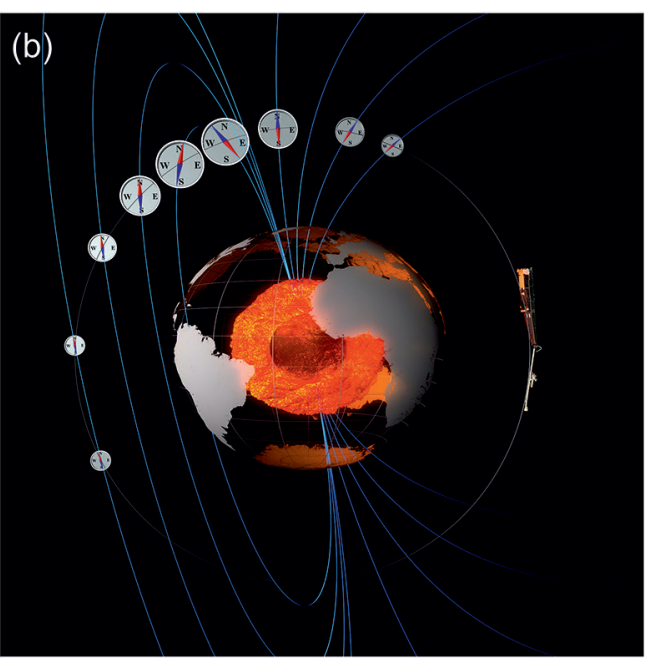

Figure 1

The way the Earth's magnetic field is created is very complex and not totally understood by scientists today. It is thought that the electrical current loop in the core does not form a perfect circle running around the equator, which is why the magnetic field is actually somewhat "tilted," by around $11^{\circ}$, away from the rotation axis of the Earth. The strength of the electrical current changes over time too, which makes the magnetic field at the Earth's surface change. Finally, the flow of the liquid metal "drags" the magnetic field westward. All these different processes combine to make the magnetic field very complicated and it is hard to predict how it changes over time. About four times every million years, the magnetic field experiences a reversal where the poles "flip over," though this takes thousands of years to happen.

\section{THE MAGNETIC FIELD AT THE EARTH'S SURFACE}

While the overall shape of the Earth's magnetic field is similar to a simple bar magnet, when you look at the magnetic field in detail, it is far more complicated. In general, a compass needle points approximately northwards, but it does not point to true North (the point around which the Earth rotates). The angle between true North and the direction a compass needle points is called declination. A compass needle points toward a location called the magnetic North pole.

The magnetic field is very useful for navigation. The Chinese used basic compasses back in the 1100 s to find direction. The first map was made by Edmund Halley, of Halley's comet fame, for use by ships sailing the Atlantic Ocean in 1699. He realized that the magnetic field changed constantly and proposed that there was a liquid layer at the center of the Earth. The magnetic North pole was discovered by James Clerk 
Ross in 1831 in Canada. However, to further complicate matters, the magnetic North pole does not stay in the same place but instead moves all the time, due to the flow of the outer core.

At present (in 2019), the magnetic North pole is still in northern Canada, but it is moving at a rate of around $50 \mathrm{~km}$ per year and will cross into northern Russia sometime in the next decade. Figure 2 shows the locations of the North and South magnetic poles from the years 1900 to 2020. Notice how quickly the North pole has moved since 2000, while the South pole has not moved by much in comparison.

\section{MAKING A MAP}

To make a map of the magnetic field is simple enough, in theory. All you need is a GPS device (such as a smartphone) to work out your exact

\section{Figure 2}

The location of the magnetic poles shown every five years (red dots) from 1900 to 2020, for the magnetic North pole (a) and the magnetic South pole (b). Notice that the magnetic north pole has moved much further and more quickly than the south magnetic pole since 1900.

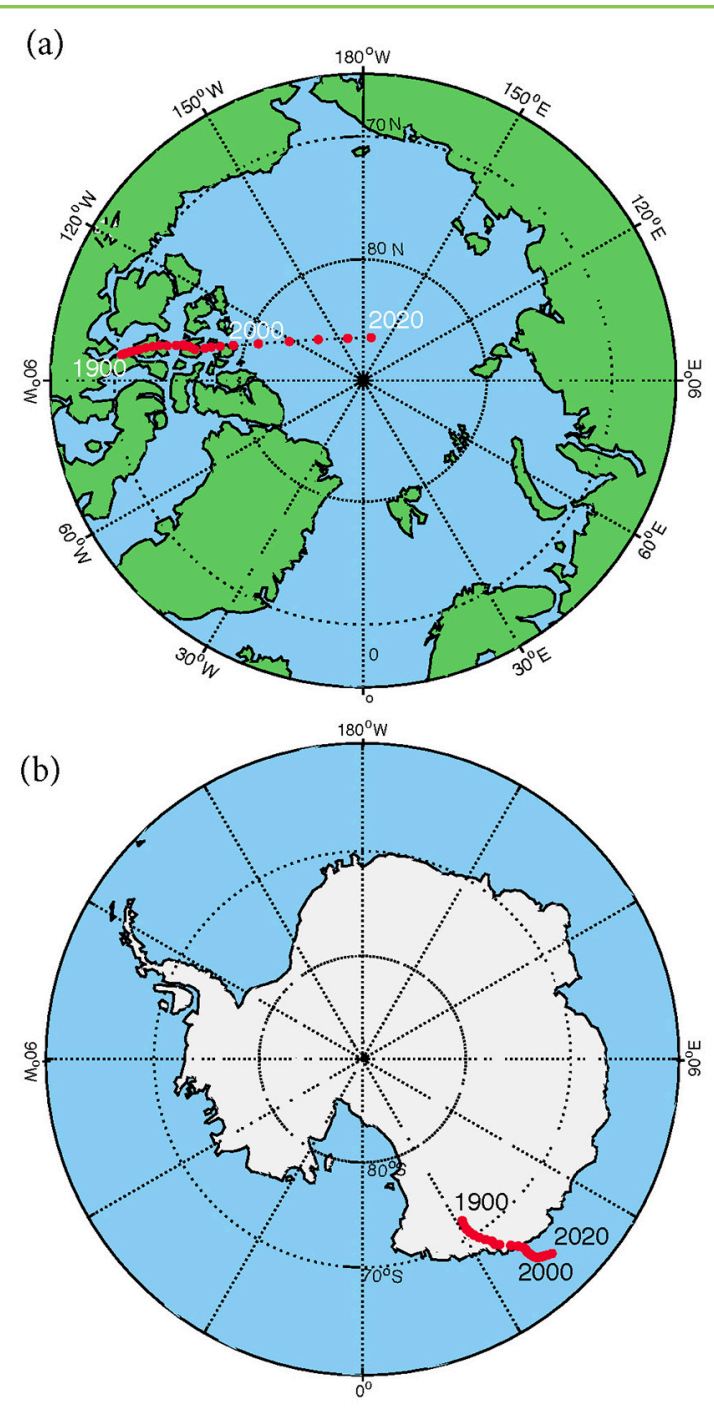

Figure 2 
location and to help you find the direction of true North. You also need a compass. First, use the GPS to work out the direction of true North. This can be done by putting two sticks in the ground along a line of constant longitude. Stand between the sticks and work out the angle between the compass needle and the true North line you made using the two sticks. Congratulations, you have measured declination! To make a map, repeat this measurement at another location and another. Do this a few million times across the entire world, including the oceans and the deserts, and your work is complete ... for a few years at least, until magnetic North moves. Obviously, this is impossible for a human to do, but it is feasible for a satellite.

Since 1999, there have been three European satellite missions to make very precise measurements of the Earth's magnetic field. Figure $1 \mathrm{~b}$ shows how a satellite senses the magnetic field coming from the outer core. The current trio of satellites, called Swarm, flies between 450 and $500 \mathrm{~km}$ above Earth's surface and travel at $8 \mathrm{~km}$ per second. It takes around $90 \mathrm{~min}$ for them to circle the Earth and they make 15 orbits per day. After 4 months, they make enough measurements across the world to create a map [2].

The satellites' measurements are collected onto a computer, where a mathematical process called inversion is used to produce a map (or snapshot) of the magnetic field at a fixed point in time. Figure 3 shows a map of declination angle for January 2019, illustrating how complicated the magnetic field really is.

As the magnetic field change is not predictable much beyond 10

Figure 3

The Declination angle for the year 2019 (in degrees), from the International Geomagnetic Reference Field (IGRF-12) model. The colors show the angle between Magnetic North and True North. White areas are where the compass points almost exactly north. Blue colors show the regions where the compass points West of True North, while the red colors show where a compass points East of True North. You can see the very complicated pattern of declination angles around the world [3]. years, these magnetic field maps get updated regularly every 5 years.

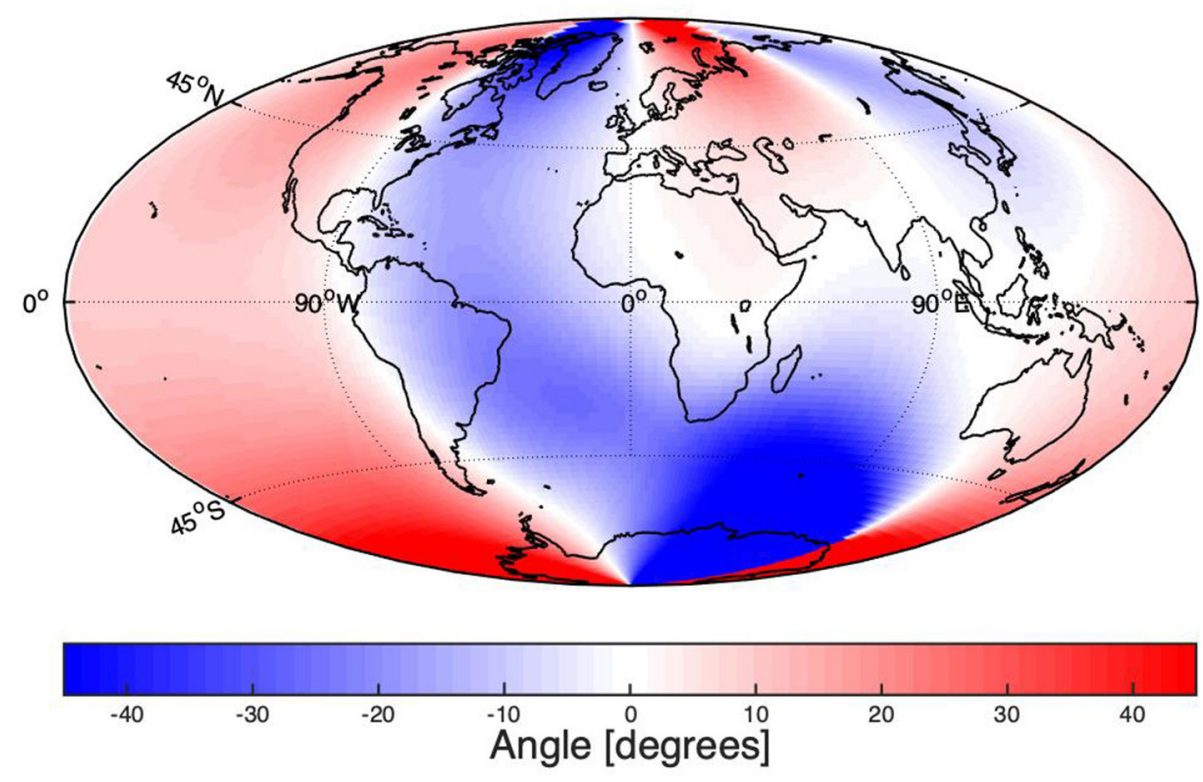

Figure 3 
Some maps are created for free by a group of scientists from around the world and are known as the International Geomagnetic Reference Field, or IGRF [3]. It is a big effort to make a good map, and takes several months of work. The latest version was released in 2015 and the next will be ready by 2020 .

\section{MAGNETIC MAP ON YOUR SMARTPHONE}

You are probably most familiar with using the Earth's magnetic field for navigation - think of ships sailing the ocean or people walking across mountains. However, if you have ever used a map on a smartphone to find where you want to go, then you have also used a map of the Earth's magnetic field.

When you open the map application, your location is usually shown as a small dot with an arrow or triangle indicating the direction you are looking. Smartphones use a built-in digital compass to work out the direction of magnetic North. However, as maps are aligned to true North, the phone's software has to correct for the declination difference. The phone uses your GPS location to work out the correct angle from a declination map, such as the IGRF. From Figure 3, you can see that, in some parts of the world, this angle can be up to $45^{\circ}$.

\section{CONCLUSION}

Making maps of the Earth's magnetic field is a complicated process that has to be repeated at least once every 5 years in order to keep the maps up to date. The maps can teach us about the outer core of Earth, and they are also useful for many practical applications that you have probably experienced such for navigating through a city with a smartphone.

\section{REFERENCES}

1. Lowrie, W. 2007. Fundamentals of Geophysics, 2nd Edn. Cambridge: Cambridge University Press.

2. Olsen, N., Hulot, G., Lesur, V., Finlay, C. C., Beggan, C., Chulliat, A., et al. 2015 The Swarm Initial Field Model for the 2014 geomagnetic field. Geophys. Res. Lett. 42:1092-8. doi: 10.1002/2014GL062659

3. Thébault, E., Finlay, C. C., Beggan, C. D., Alken, P., Aubert, J., Barrois, O., et al. 2015. International Geomagnetic Reference Field (IGRF): the 12th generation. Earth Planets Space 67:79. doi: 10.1186/s40623-015-0228-9 
SUBMITTED: 31 October 2018; ACCEPTED: 19 February 2019;

PUBLISHED ONLINE: 07 March 2019.

EDITED BY: Anna Regoutz, Imperial College London, United Kingdom

CITATION: Beggan CD (2019) Making a Map of the Earth's Magnetic Field. Front. Young Minds 7:42. doi: 10.3389/frym.2019.00042

CONFLICT OF INTEREST STATEMENT: The author declares that the research was conducted in the absence of any commercial or financial relationships that could be construed as a potential conflict of interest.

COPYRIGHT (c) 2019 Beggan. This is an open-access article distributed under the terms of the Creative Commons Attribution License (CC BY). The use, distribution or reproduction in other forums is permitted, provided the original author(s) and the copyright owner(s) are credited and that the original publication in this journal is cited, in accordance with accepted academic practice. No use, distribution or reproduction is permitted which does not comply with these terms.

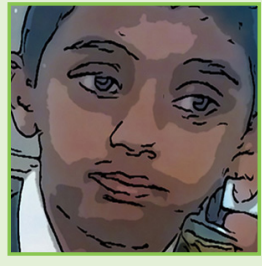

\section{YOUNG REVIEWER}

\section{SASYAK, AGE: 10}

I am 10 years old student from India. I am an avid reader of several genres of books. I am a keen participant in quiz contests and olympiads, and a spell bee champion. I attend football classes and enjoy cycling.

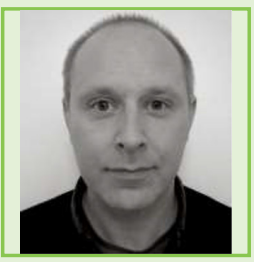

\section{AUTHOR}

\section{CIARÁN D. BEGGAN}

I am a Senior Scientist at the British Geological Survey. I work in the Geomagnetism team in Edinburgh. They study all aspects of the Earth's magnetic field, from the core to outer space. I look at why the magnetic field changes over time and how to improve our ability to forecast magnetic field changes accurately beyond 5 years. I also look the application of magnetic field measurements to understanding how the Earth and Sun's magnetic fields affect each other, particularly when the aurora borealis (Northern Lights) are visible. *ciarabgs.ac.uk 